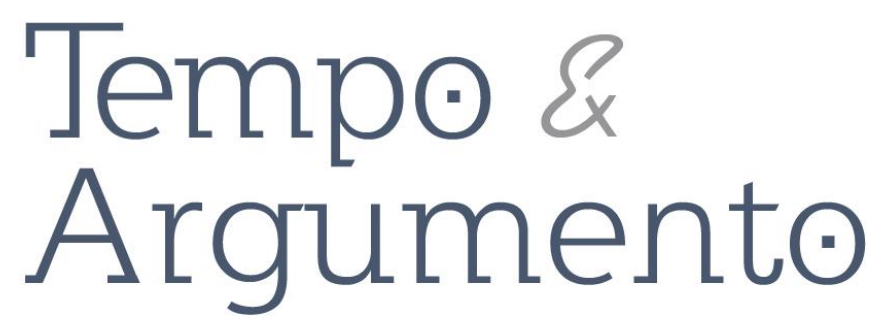

\title{
Relações de Gênero nos espaços do Direito: experiências
} \section{compartilhadas}

\section{Resenha da obra:}

SCHINKE, Vanessa Dorneles (Org.). A violência de gênero nos espaços do Direito: Narrativas sobre ensino e aplicação do direito em uma sociedade machista. Rio de Janeiro: Lumen Juris, 2017. 388 p.

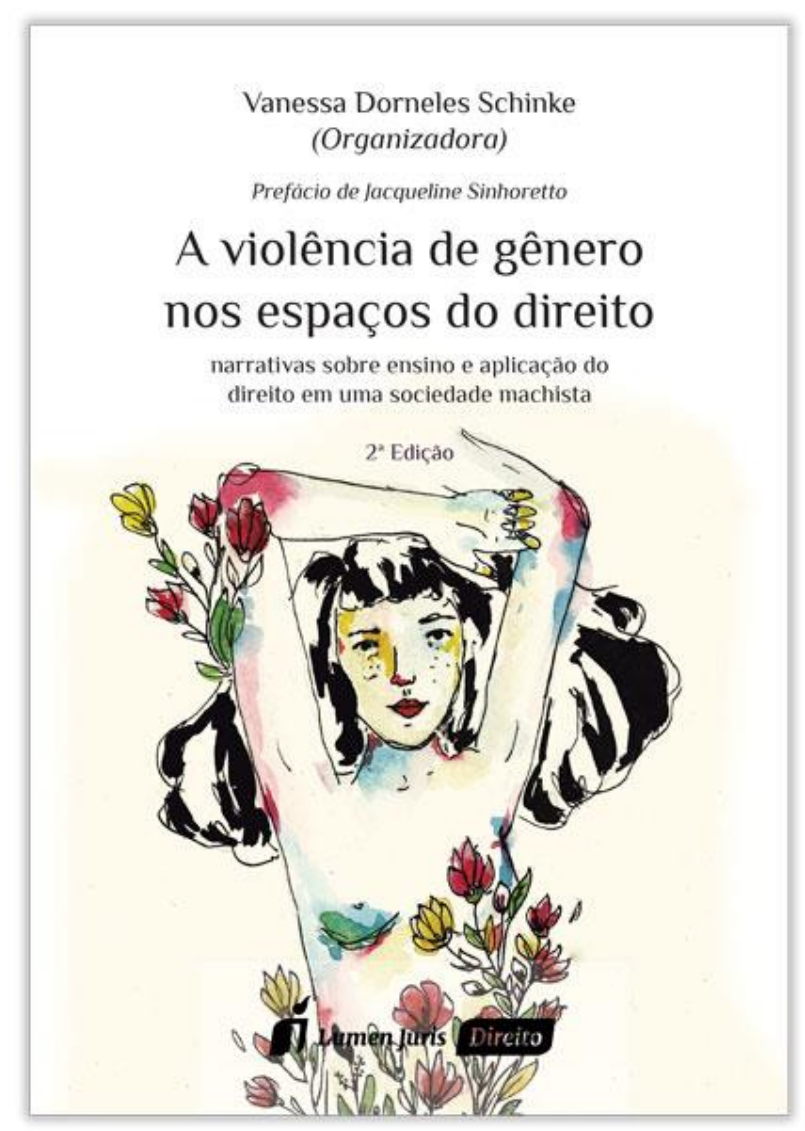

\section{Autora da resenha}

Jade Liz Almeida dos Reis

Mestranda em História na Universidade do Estado de Santa Catarina (UDESC).

Florianópolis, SC - BRASIL jjadeliz@gmail.com orcid.org/0000-0002-6439-661X

\section{Para citar esta resenha:}

SCHINKE, Vanessa Dorneles (Org.). A violência de gênero nos espaços do Direito: Narrativas sobre ensino e aplicação do direito em uma sociedade machista. Rio de Janeiro: Lumen Juris, 2017. 388 p. Resenha de: REIS, Jade. Relações de Gênero nos espaços do Direito: experiências compartilhadas. Revista Tempo e Argumento, Florianópolis, v. 11, n. 27, p. 523 - 529. maio/ago. 2019. 
Diversos relatos de mulheres advogadas sobre o seu ofício diário mostram que durante sua trajetória jurídica lhes são apresentados empecilhos e violências simbólicas que envolvem as relações de gênero. Não coincidentemente, a coletânea de artigos organizada pela professora e doutora em Direito Vanessa Dorneles Schinke, objeto desta resenha, aborda experiências de mulheres da área do Direito, em carreiras absolutamente marcadas pelos estereótipos historicamente construídos nas relações de gênero.

O livro, lançado no ano de 2017, é dividido em três partes, sendo a primeira delas o “Prelúdio", na qual estudantes de Direito narram suas trajetórias e experiências da vida universitária, bem como expressam as relações complexas de poder que permeiam estes espaços. O exercício de questionar e historicizar a situação das mulheres está presente nesta parte, assim como em todo o livro, bem como o de refletir sobre o papel de educadoras e operadoras do Direito em uma sociedade machista. Para as autoras, partindo da perspectiva de que, por muito tempo, este campo científico foi essencialmente masculino em termos de representatividade, e tendo em vista a luta das mulheres pela democratização do ensino superior e do mercado de trabalho, sua presença nestes espaços e no espaço público de maneira geral, estudando, profissionalizando-se, adentrando carreiras e cargos públicos, se apresenta como um avanço no que se refere ao árduo processo de ocupação dos espaços considerados pela norma patriarcal como "masculinos".

A segunda parte, intitulada "Andante", conta com doze artigos escritos por professoras, estudantes de graduação, pós-graduação e operadoras do Direito. Esta tem como foco temático questões que, como afirmam, não encontram espaço na circulação acadêmica do campo do Direito, mas fazem parte das experiências e cotidianos destas mulheres no âmbito universitário, como, por exemplo, nas salas de aula e instâncias politicamente deliberativas do meio universitário. As autoras buscam, por meio da narrativa de suas experiências, problematizar a naturalização de práticas violentas e machistas no ensino do Direito.

Segundo estas autoras, a condição de gênero expressa nas relações sociais no campo do ensino do Direito é definida historicamente a partir da socialização e das definições impostas pela sociedade patriarcal, gerando assim o problema da ausência de 
reconhecimento e a descrença no seu potencial de desenvolvimento na área jurídica. Roberta Baggio, professora do curso de Direito da UFRGS relatou em seu artigo que, na banca de um concurso público que prestou, ouviu de um membro a seguinte frase "como pode você ser mulher e ter um currículo com tantas experiências acadêmicas ao mesmo tempo?" (BAGGIO, 2017, p. 66), demonstrando assim o grau de incapacitação destinado às mulheres em suas avaliações de emprego, o que é por vezes um fator determinante em suas trajetórias profissionais. A autora afirma que na medida em que o ensino do Direito contribui para tais práticas, formam-se juristas que naturalizam as violências de gênero, culpabilizam e responsabilizam as mulheres pela cultura machista em casos de opressão.

As violências físicas e simbólicas existentes nos "trotes" nos cursos de Direito são, também, tema de abordagem nesta parte do livro. Violências estas que, muitas vezes advindas dos professores, envolvem provocações e incitações machistas, homofóbicas, transfóbicas e racistas, nas quais os corpos femininos são objetificados. Estudantes e professoras se organizam em ações contra os episódios de extremo machismo e preconceitos na universidade através de cartas de repúdio, escrachos, atos e movimentações, criação de coletivos e meios de solidariedade e articulações via internet e redes sociais. No entanto, denunciam as poucas oportunidades de debater gênero e violência nos cursos de Direito, bem como nos demais cursos de graduação e pósgraduação. A pesquisa realizada pela advogada Luana Pereira com estudantes da faculdade de Direito da UFRGS revela que 69\% destas afirmaram já ter sido vítimas de práticas machistas na academia, 52\% afirmaram ter passado por situações de assédio moral e 19,4\% assédio sexual (PEREIRA, 2017, p. 94). Muitos dos casos de extrema violência de gênero que ocorrem nestes espaços têm repercussão em nível público, atingindo assim um maior número de mulheres, formando uma rede de sociabilidades e luta contra tais práticas. Todavia, o silenciamento dos assédios continua sendo uma realidade para as mulheres, professoras, estudantes e funcionárias técnicas e terceirizadas. Segundo a advogada Alice Abelar, na PUCRS, dentre 126 professores de graduação, $26 \%$ são mulheres. Apenas 20\% na Pós-graduação em Direito e 10\% na Pósgraduação em Ciências Criminais. Estes dados evidenciam a dificuldade do acesso das 
mulheres ao cargo de professora universitária, enquanto que não há discussão e questionamento sobre o assunto que não sejam impulsionados pelas mulheres, e daí a importância de sua representatividade.

A partir da leitura da obra é possível observar que entre as décadas de 1970 e 1990, com a crescente expansão das universidades, as mulheres passam a ter maior expressão neste campo, ainda que com as demarcações de classe e raça. Problematizar a violência de gênero nestes espaços deve considerar a gritante ausência de mulheres negras, indígenas e deficientes no ensino superior, que tem se democratizado processualmente a partir das lutas dos Movimentos Sociais e dos incentivos governamentais, como, por exemplo, a Lei n. ${ }^{\circ} 12.711$ de 2012 (Lei de Cotas).

O machismo dentro da militância do movimento estudantil também é apontado pelas autoras, na medida em que os estudantes homens ocupam cargos de representatividade, interrompem as falas de companheiras do movimento, não levam em consideração suas boas ideias, considerando-as apenas auxiliares de determinadas funções dentro das organizações.

As mulheres encontram-se em árduo combate político na academia, espaço que durante muito tempo fora homogeneizado pela presença masculina. Por isso a importância dada às professoras e militantes deste espaço na construção de diferentes futuros para estas mulheres. A terceira parte da coletânea, intitulada "Adagio", reúne o total de onze artigos que apresentam criticamente a disputa de gênero no interior do judiciário, no qual a presença das violências simbólicas se destaca sobremaneira. Nesta parte da obra em questão, são narrados diversos casos que apresentam a naturalização e o descaso com as violências de gênero expressas no campo.

Marta Machado e Fernanda Matsuda, em seu estudo sobre a representação das mulheres nos processos judiciais no Sistema de Justiça Criminal, apontam que o discurso sobre as mulheres apresenta figuras dicotômicas idealizadas de mulher, sendo a "boa mulher" de família, boa esposa, dedicada, trabalhadeira, e a "mulher desafiadora, festeira, nervosa" (MACHADO e MATSUDA, 2017, p. 196), enquanto que os homens são sempre representados como pais de família, honestos e trabalhadores. As violências cometidas por estes, segundo as autoras, são rotineiramente justificadas nas salas de 
audiência pelo "mau comportamento" das mulheres, e apontadas como comportamento isolado dos homens. Estas demarcações interferem sobremaneira nos desfechos processuais das ações, legitimando, por vezes, danos irreparáveis às vidas de mulheres que são vítimas das violências de gênero, raça, etnicidade e demais preconceitos.

Segundo as autoras, os órgãos do Sistema Judiciário não reconhecem tais violências, e portanto não incidem os dispositivos legais específicos para os respectivos casos. Neste sentido, percebemos a desigualdade de gênero do exercício de poder nas instâncias do Judiciário brasileiro, o que está expresso, também, na baixa representatividade das mulheres nas esferas de decisão das organizações jurídicas, igualmente abordadas nesta parte do livro. Da mesma forma, ocorre nos escritórios de advocacia, nos quais a pesquisadora Patrícia Bertolin observou alto número de evasão de mulheres, ainda que nas entrevistas realizadas com os advogados homens que trabalham nestes espaços tenha sido frequente a negação de qualquer tipo de discriminação de gênero. A maternidade nesta profissão parece ser um dos principais problemas aparentes que obstacularizam a ascensão das mulheres no meio, como um "problema a ser resolvido". Nesse sentido, é consenso entre as autoras que a advocacia é uma profissão que vem se femilinizando, mas ainda nos padrões machistas excludentes, obrigando as mulheres a afirmar e provar o tempo todo sua competência e eficiência profissional.

O livro "A violência de gênero nos espaços do Direito" é uma obra sobre experiências cotidianas. Um manifesto de mulheres feministas. Mulheres que lutam pela igualdade e promoção de direitos. Trata-se de pesquisadoras guiadas pela epistemologia feminista, que buscam problematizar seus posicionamentos e lugares de fala de forma interseccional, considerando os diferentes tipos de opressão decorrentes dos diversos marcadores sociais historicamente constituídos em nossa sociedade. Suas narrativas expressam uma série de subjetividades, com as quais se identificam o tempo todo as mulheres que as leem. Estas narrativas, como afirmam diversas vezes as autoras, saem da posição estritamente acadêmica, na medida em que tratam de experiências de mulheres que vivenciam as violências e demarcações de gênero não apenas nos espaços do Direito, mas na sociedade como um todo. A pesquisadora e organizadora da obra, Vanessa Dorneles Schinke, apontou ao encerrar as discussões realizadas no livro: “Aqui não há 
linha clara entre sujeito e objeto, empiria e teoria. O resultado é uma complexa composição que se retroalimenta da colaboração entre diversas pessoas - verbais e de carne e osso" (SCHINKE, 2017, p. 367)

São diversos os arcabouços teóricos sobre Relações de Gênero e Teoria Feminista, específicos de cada temática abordada, utilizados nos 23 artigos que compõem a obra. Dentre eles, estão os que possibilitam articular as categorias como gênero e poder, através dos escritos de Michel Foucault e Joann Scott, por exemplo, gênero, raça e interseccionalidade, através dos estudos das teóricas Kimberlé Crenshaw e Helena Hirata, por exemplo, gênero e classe social, utilizando como referencial teórico os escritos da socióloga Heleieth Saffioti, dentre outras. Bem como referenciais teóricos clássicos dos estudos de gênero, como Simone de Beauvoir, Judith Butler e Bell Hooks, por exemplo. As autoras partem, em comum, da já mencionada epistemologia feminista, na medida em que têm como proposta a mudança do paradigma referencial das experiências compartilhadas pelos sujeitos e abordadas nas pesquisas científicas. A lógica da narrativa de suas experiências vivenciadas no campo alinha-se na epistemologia feminista, na medida em que justamente descola a figura masculina como detentora principal das discussões acerca das relações no meio jurídico.

A universidade e os demais campos do Judiciário são entendidos por estas pesquisadoras como espaços privilegiados da reprodução de uma cultura machista e sexista, mas são também expressos como espaços de luta e resistência de mulheres pela democratização dos espaços do Direito. 
Recebido em 18/03/2019 Aprovado em 18/04/2019

Universidade do Estado de Santa Catarina - UDESC Programa de Pós-Graduação em História - PPGH Revista Tempo e Argumento Volume 11 - Número 27 - Ano 2019 tempoeargumento@gmail.com 